\title{
Optimization of Kraft Black Liquor Treatment Using Ultrasonically Synthesized Mesoporous Tenorite Nanomaterials assisted by Taguchi Design
}

\author{
Mohammadreza Kamalia,b,c, Mohammadreza Khalajb,c, M. Elisabete V. Costac, Isabel Capela ${ }^{b^{*} \text {, }}$ \\ Tejraj M. Aminabhavid ${ }^{* *}$ \\ a KU Leuven, Department of Chemical Engineering, Process and Environmental Technology Lab, \\ J. De Nayerlaan 5, 2860, Sint-Katelijne-Waver, Belgium \\ b Department of Environment and Planning, Center for Environmental and Marine Studies, \\ CESAM, University of Aveiro, 3810-193 Aveiro, Portugal \\ c Department of Materials and Ceramics Engineering, Aveiro Institute of Materials, CICECO, \\ University of Aveiro, 3810-193 Aveiro, Portugal \\ d Pharmaceutical Engineering, Soniya College of Pharmacy, Dharwad 580-002 India
}

\begin{abstract}
This study explored the removal of total organic carbon (TOC) from the highly polluted pulp and paper industry black liquor effluents by utilizing the mesoporous tenorite $(\mathrm{CuO})$ nanomaterials $(\mathrm{NMs})$ prepared by ultrasonic irradiation. The catalyst prepared was fully characterized in terms of chemical, structural, microstructural, and surface characteristics. The optimization of the TOC removal was performed using the Taguchi methodology and by manipulating the operational parameters such as reaction time, initial $\mathrm{pH}$, temperature, sonication time, the dosage of NMs as well as the effect of solar irradiation on the activation of tenorite NMs (30-35 nm and Brunauer, Emmett, Teller (BET) surface area $=35 \mathrm{~m}^{2} / \mathrm{g}$ ). TOC removal of $84 \%$ of the black liquor was achieved under mild conditions of room temperature and pressure of $5 \mathrm{~g} / \mathrm{L}$ of the catalyst in $24 \mathrm{~h}$ of treatment, including $12 \mathrm{~h}$ of solar irradiation which is the first report in the literature on treatment of black liquor Kraft mill effluents using tenorite NMs under the solar irradiation by employing the Taguchi methodology.

Keywords: Tenorite (CuO) nanomaterials, advanced oxidation process (AOPs), black liquor, pulp and paper industry, Taguchi methodology.

\section{Introduction}

The advent of new nanomaterials has made a major contribution to the identification of new processes to deal with recalcitrant environmental contaminants [1-4]. Tenorite $(\mathrm{CuO})$ is a material of high importance due to its unique chemical, electrical, and optical properties, making it an excellent candidate for several applications, such as heterogeneous catalysis [5-9], energy conversion [10] and bio-

* Corresponding authors: icapela@ua.pt

** Corresponding authors: aminabhavit@gmail.com
\end{abstract}


detection [11], etc. Various synthesis methodologies have been reported for copper oxide nanomaterials (NMs) to optimize their performance [12-17]. For instance, Alavi and Morsali [18] prepared $\left\{\left[\mathrm{Cu}_{2}(\mathrm{BDC})_{2}(\right.\right.$ dabco $\left.)\right]$. $\left.2 \mathrm{DMF} .2 \mathrm{H}_{2} \mathrm{O}\right\}$ NMs using ultrasonic irradiation and used it as a precursor to synthesis copper oxide nanoparticles. Within the context of catalytic applications, the NMs of $\mathrm{CuO}$ have the potential to deal with the highly polluted and complex industrial effluents.

In many chemical industries, the pulp and paper industry is considered the main user and producer of raw materials (wood and non-wood), and a large volume of effluents is generated containing an enormous amount of phenolic compounds [19,20]. The amount of wastewater produced and the load of pollutants depend on several factors, such as the raw materials used, the production scale, and the employed technologies for the production of pulp and/or paper [21,22]. Compared to large mills (>10ot/d), small and medium-sized pulp and paper mills (<10ot/d) generate smaller amounts of effluents but produce higher pollution load in the generated effluents [23]. This is mainly due to the lack of infrastructure for the recovery of chemicals necessary for the production process [24-27]. Kraft pulp (KP) is an alkaline pulping process widely used to cook wood chips in white liquor, a solution of sodium hydroxide and sodium sulfide [27]. Pulping processes based on wood and non-wood raw materials usually produce large volumes of black liquor (BL). Phenolic compounds are among the main constituents of BL content due to the presence of soluble lignin [28]. Currently, BL is generated in large volumes as a byproduct in both wood and non-wood pulping processes [21,27,29]. Conventionally, BL produced in the integrated pulp and paper mills is concentrated and incinerated in an oven to recover chemicals such as $\mathrm{Na}_{2} \mathrm{CO}_{3}$ and $\mathrm{Na}_{2} \mathrm{~S}$ as the molten smelt and to drive energy from the residual organic matter [3o]. Air pollution and the generation of odors are the first consequences of this process [31]. Furthermore, this process requires high investments, high operating costs, in addition to the instability of the process and the risks of explosion [30]. This poses problems for medium and small pulp mills to adopt such treatments for their by-products. Such industries generally discharge the effluents without efficient treatment into the environment [28]. Therefore, novel strategies are needed for the treatment of BL from the pulp and paper industry. Schmitt et al. (2017)[32] employed the anion exchange resins coupled with a subsequent electrochemical treatment to remove low molecular weight phenolic compounds. However, due to the complex nature of $\mathrm{BL}$, the application of the anaerobic biological treatment to these effluents may not result in a complete conversion of organic matter into biogas, in addition to the fact that part of the organic components of these effluents remains untreated [33-36]. One reason for the low biodegradability of $\mathrm{BL}$ is the presence of compounds such as lignin derivatives, tannin, resins, etc. which are highly toxic to methanogenic microorganisms [35].

The present study is one of the first investigations to sonochemically synthesized tenorite NMs in order to optimize the TOC removal from the diluted BL real effluent. The Taguchi method was employed to identify the effect of operational parameters on the removal of TOC from the BL. Taguchi's methodology allowed us to identify the optimum level for the influence parameters while using the minimum number of experiments [37]. 


\section{Experimental}

\subsection{Characterization of the effluent}

The black liquor effluents were received from a medium-size Portuguese pulp and paper mill. Sampling and analysis of effluents were performed according to standard methods for the analysis of water and wastewater [38]. Total organic carbon (TOC) was measured using a multi N/C (analytikjena, Germany). A Consort P6o2 was used to measure the $\mathrm{pH}$, electrical conductivity (EC), and the total dissolved solids (TDS) of the effluents that were measured before and after the treatment.

\subsection{Synthesis and characterization of nanomaterials}

Copper (II) acetate $\left(\mathrm{Cu}\left(\mathrm{CH}_{3} \mathrm{COO}\right)_{2}\right)$ (98\%) was purchased from Sigma-Aldrich and used as received. Sodium hydroxide $(\mathrm{NaOH})(\geq 98.0 \%)$ was purchased from JMGS, Portugal. All solutions were prepared with deionized water. $100 \mathrm{~mL}$ of a solution containing $4.9 \mathrm{gr}$ of $\mathrm{Cu}\left(\mathrm{CH}_{3} \mathrm{COO}\right)_{2}$ in deionized water (solution A) was stirred for 5 min and subjected to ultrasonic irradiation (UI) using an ultrasound horn (Hielscher, UP2oos W, $24 \mathrm{kHz}$ ) under the constant magnetic stirring at $60{ }^{\circ} \mathrm{C}$. The amplitude for sonication was adjusted to $60 \%$, providing a theoretical dissipation rate of $120 \mathrm{~W}$. In parallel, a solution containing $5 \mathrm{gr}$ of $\mathrm{NaOH}$ in $100 \mathrm{~mL}$ of deionized water (solution B) previously stirred for 5 min was added to solution A with the help of a Watson Marlow (120U/R) peristaltic pump that guarantees a constant rate of addition, at room temperature. After delivering the entire sodium hydroxide solution, the resulting mixture was stirred in the reactor for another 30 minutes. The precipitated brown particles were then filtered using Whatman filter papers and dried at $60{ }^{\circ} \mathrm{C}$ for $12 \mathrm{~h}$ and finally collected for characterization studies.

The X-ray powder diffraction (XPRD) (Panalytical X'Pert PRO 3, Netherlands) analysis was employed to examine the crystalline nature of the products. The continuous scan from $20^{\circ}$ to $80^{\circ} 2 \theta$ was conducted at a scan rate of $2^{\circ} 2 \theta / \mathrm{min}$.

SEM images and energy-dispersive X-ray spectra (EDS) were obtained using a scanning electron microscopy (SEM) (Hitachi SU-70). After ultrasonic irradiation of the slurry containing the prepared nanoparticles (in ethanol) for 10 min (to allow the particles to be separated), a drop of the slurry was placed on the grid and allowed to dry and then used for the characterization. Nitrogen gas adsorptiondesorption isotherms were obtained using a Micromeritics Gemini 2380 equipment (USA). The powder samples were degasified at $120{ }^{\circ} \mathrm{C}$ overnight before the measurement. The obtained adsorption/desorption data were fitted to Brunauer, Emmett, Teller (BET) isotherm equation to determine the specific surface area of the particles [39,40]. To estimate the pore size distribution, the Barrett, Joyner, Halenda (BJH) method, derived from the Kelvin equation [41], was employed.

UV-Vis spectra of the final products were also recorded with a UV-Vis scanning spectrometer (T80+, PG Instruments, UK). According to UV absorption, the energy band gap (Eg) was measured using eq. (1):

$$
E g=\frac{h c}{\lambda}
$$


where $\mathrm{h}$ is Plank constant $(h=6.626 \times 10-34 \mathrm{~J} \mathrm{~s}), c$ is the speed of light $(\mathrm{c}=3.0 \times 108 \mathrm{~m} / \mathrm{s})$ and $\lambda$ is cut off wavelength $(\lambda=410.57 \times 10-9 \mathrm{~m})[42,43]$.

Particle zeta potential (ZP) was measured using a zeta sizer device (Zetasizer Nano ZS, Malvern, UK). The diluted aqueous suspensions of the nanomaterials were prepared under ultrasonic irradiation in an ultrasonic cleaning bath (Model Sonoswiss 6lt, Switzerland). The $\mathrm{pH}$ of the nanoparticle suspensions was adjusted in acidic and alkaline ranges using $\mathrm{HCl}$ or $\mathrm{NaOH}$, respectively.

\subsection{Design of the Experiments}

A Taguchi L18 statistical design [44] (Table 1) was employed to investigate the effects of operational parameters on the removal of TOC from the studied effluents. Signal-to-noise ratio $(\mathrm{S} / \mathrm{N})$ using larger values of $\mathrm{S} / \mathrm{N}$ was employed to determine the relative importance of the parameters. The design of the experiment (DOE) is presented in Table 1 (part A) where five experimental parameters were explored, i.e., reaction time, $\mathrm{pH}$, temperature, sonication time (\% of total reaction time), and dosage of the NMs in the reaction medium. Eq. (2) was used to identify the relative importance of each parameter, calculating the $\mathrm{S} / \mathrm{N}$ ratio. In this equation, $Y_{i}$ is the response data of the Taguchi statistical design, and $\mathrm{n}$ represents the number of experiments [45,46]. Per the results achieved in the Taguchi experimental design, complementary experiments were also designed (Table 1, part B) to achieve higher removal efficiencies by manipulating the most effective parameters as:

$$
\frac{S}{N}[d B]=-10 \log \frac{1}{n}\left(\sum_{i=1}^{n}\left(Y_{i}\right)^{2}\right)
$$

Table 1. L18 orthogonal array of experiments including the studied parameters (part A) and the complementary experiments (part B).

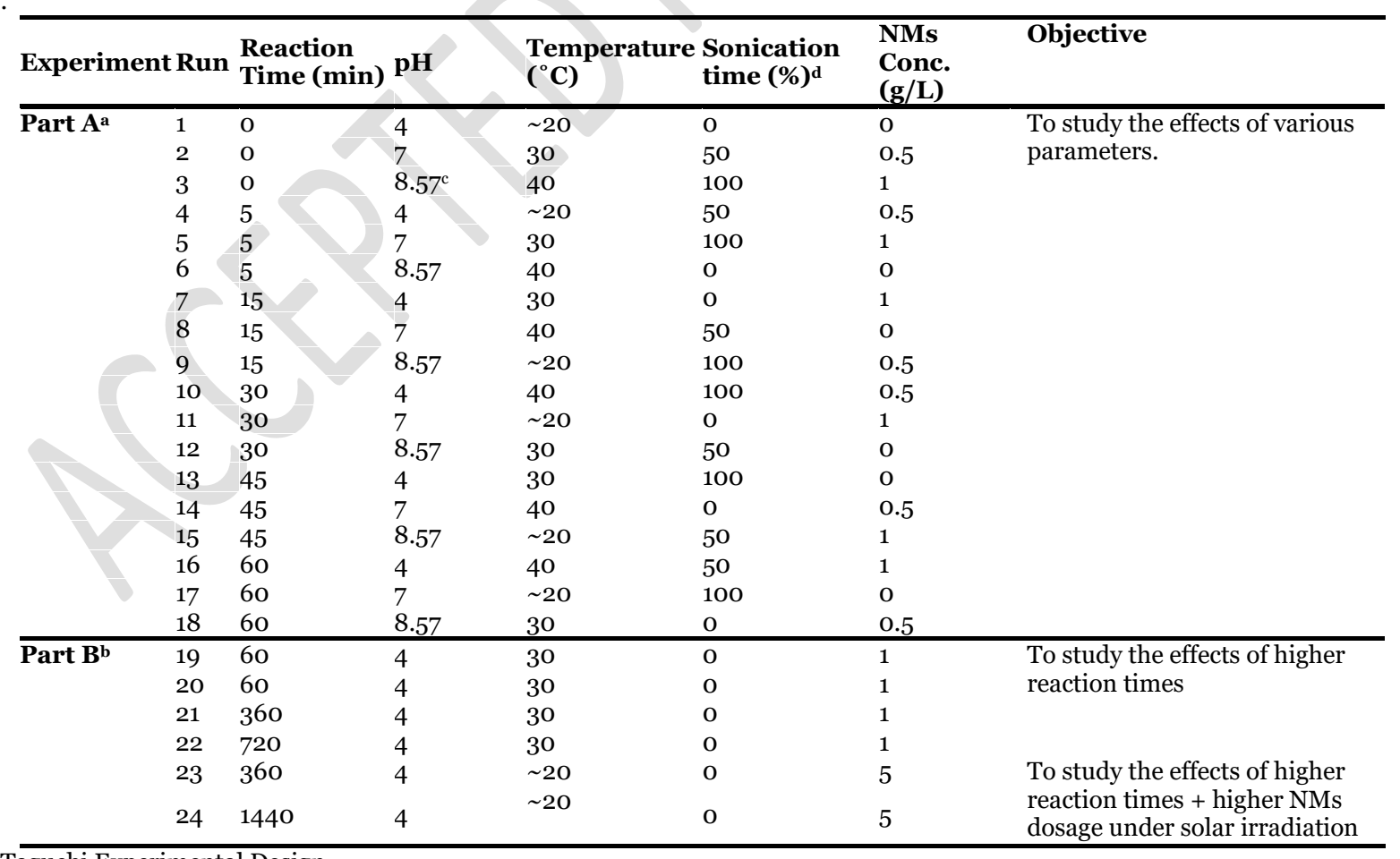

a. Taguchi Experimental Design.

b. Complementary Experiments. 
c. Natural $\mathrm{pH}$ of the black liquor effluents.

d. Sonification time measured as a percentage of the total reaction time

Batch tests for the removal of TOC were carried out in $300 \mathrm{~mL}$ round bottom flasks equipped with overhead mechanical stirring (IKA Eurostar 40) at 400 rpm speed under room visible light at 720 lux. Experiments were performed in an ultrasonic cleaning bath (Branson 42, USA) equipped with a temperature control system. The $\mathrm{pH}$ of the reaction medium was adjusted using sulfuric acid $(1 \mathrm{~N})$ and the light intensity was measured using a multi-function environment meter (ST-8820, REED, USA). Experiments including solar irradiation were performed under direct sunlight ( 16000 lux $)$ on partially sunny days in June at Aveiro, Portugal. The materials employed were recovered from the treated effluents via filtration using Whatman filter paper having the appropriate pore sizes and then used for recycling purposes.

\section{Results and discussion}

\subsection{Characterization of the effluents}

The primary physical and chemical characteristics of the diluted BL effluents prior to experiments are shown in Table 2.

Table 2. Characteristics of diluted BL effluents.

\begin{tabular}{lll}
\hline Effluent Parameter & Value & Unit \\
\hline pH & 8.57 & - \\
TDS & 2670 & $\mathrm{mg} / \mathrm{L}$ \\
TOC & 3516 & $\mathrm{mg} / \mathrm{L}$ \\
Chemical Oxygen Demand (COD) & 4900 & $\mathrm{mg} / \mathrm{L}$ \\
EC & 4.96 & $\mathrm{~S} / \mathrm{cm}$ \\
Salinity & 2700 & $\mathrm{mg} / \mathrm{L}$ \\
\hline
\end{tabular}

\subsection{Characterization of the nanomaterials}

XRD pattern of the synthesized powders is presented in Fig. 1 where reflection peaks are indexed with the help of JCPDS cards. The XRD profile displayed sharp and intense peaks between 30 to $40^{\circ} 2 \theta$ followed by other less intense peaks, all of which are attributed to tenorite with the monoclinic crystalline structure according to JCPDS: 00-041-0254 [47,48]. In addition, no secondary phase or impurity can be identified within the detection limits of the equipment.

SEM micrographs of the synthesized tenorite powders are presented in Fig. 2, a. As observed, the sample consists of individual rounded particles homogeneously dispersed [49] with an average size in the range of 30-35 $\mathrm{nm}$. EDS of the sample presented in Fig. 2, b confirm that copper and oxygen are the only elements detected in the sample. A specific surface area as large as $35 \mathrm{~m}^{2} / \mathrm{g}$ was measured by the gas adsorption, reflecting a relatively high specific surface area of the synthesized tenorite particles. The adsorption/desorption isotherms are displayed in Fig. 3. A typical hysteric behavior of mesoporous materials is clearly evidenced for the synthesized tenorite NMs. The shape of the adsorption/desorption curves allows the hysteresis loop to be classified as type H1 (IV) as per the IUPAC classification [50]. This type of loop is often associated with the porous materials with well-defined cylindrical-like pore channels or with spherical particles with uniform shape and size [51]. The average pore width was calculated based on the $\mathrm{BJH}$ method and a value of $13.2 \mathrm{~nm}$ was obtained, indicating that the synthesized NMs are mesoporous. The surface area associated with these tinny pores may be also contributing to the large specific 
surface area $\left(35 \mathrm{~m}^{2} / \mathrm{g}\right)$ of tenorite NMs. The mesoporous structure of nanomaterials can be attributed to ultrasonic irradiation during the synthesis of NMs. It may be possible that the cavitation of bubbles resulting from the ultrasonic irradiation might have caused the formation of a large number of tinny pores in nanomaterials [52].

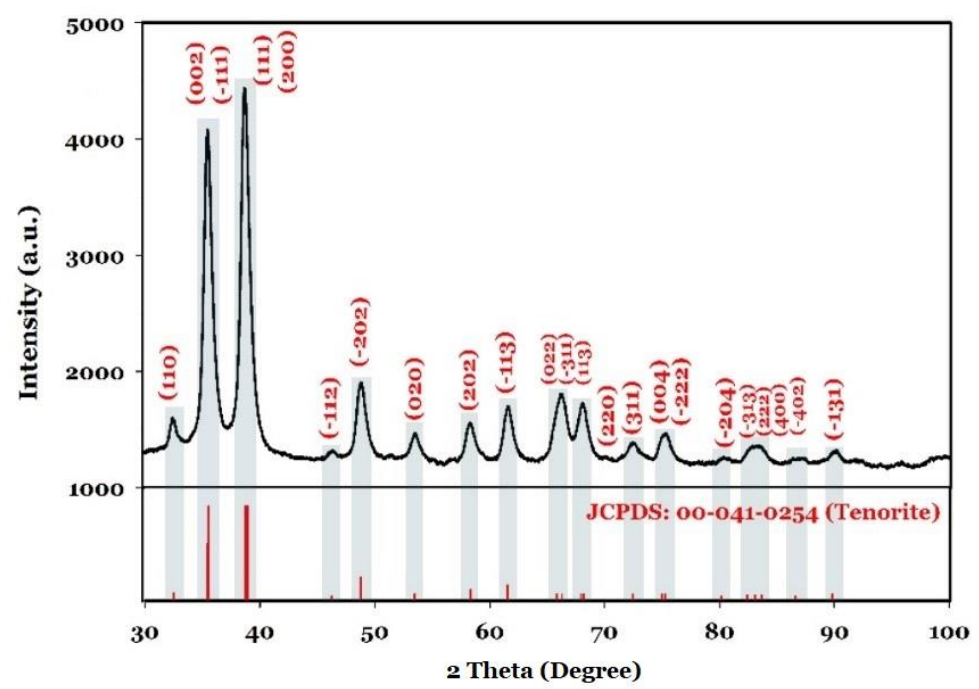

Fig. 1.

XRD patterns of the synthesized Tenorite nanomaterials.

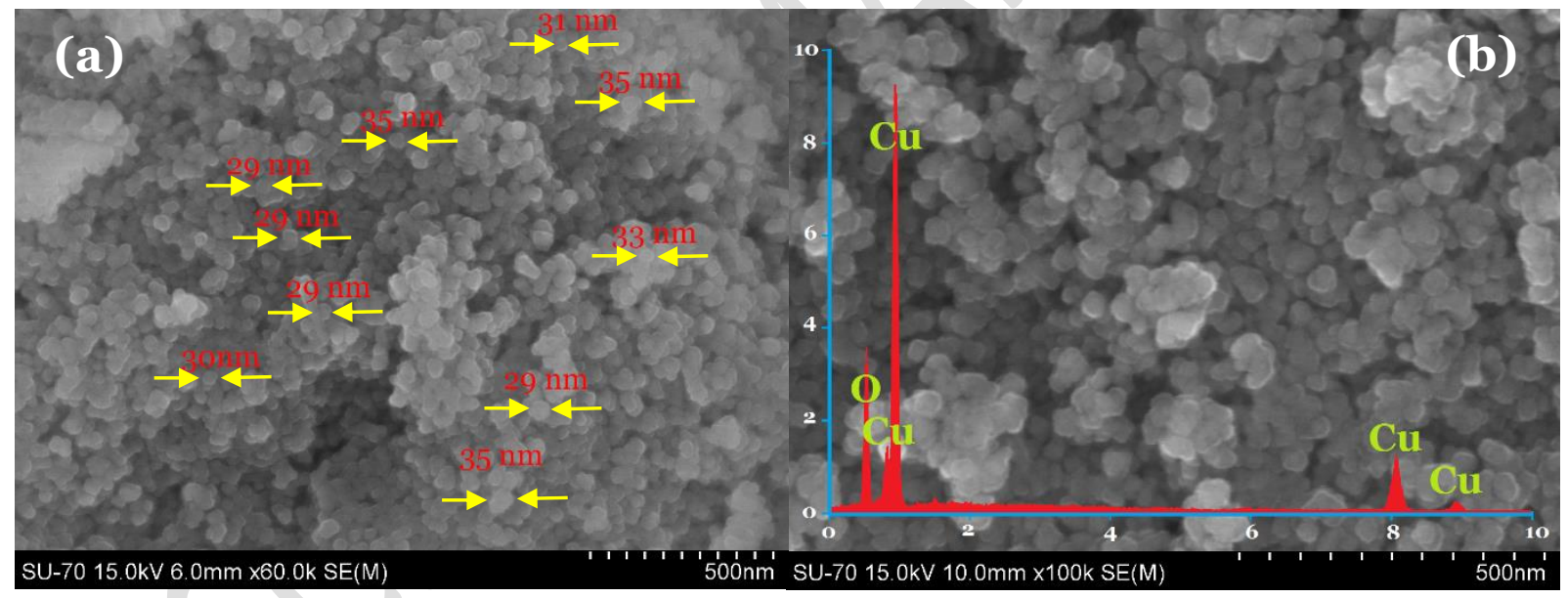

Fig. 2.

SEM image (a) and EDS spectrum (b) of the Tenorite nanomaterials synthesized in this study.

Figure 4 shows the UV-visible spectrum at room-temperature of tenorite NMs synthesized under ultrasonic irradiation. A wide spectrum ranging from $800 \mathrm{~nm}$ to $200 \mathrm{~nm}$ reveals a typical absorption peak of tenorite at $\sim 340 \mathrm{~nm}[47,48]$, while the optical band gap of tenorite NMs was calculated to be $3.6 \mathrm{eV}$. As per the literature, the expected energy band gap for nano $\mathrm{CuO}$ materials [53] may be around $4 \mathrm{eV}$. As can be observed in Fig. 4, there is a blue shift for the synthesized nanoparticles adsorption compared to that of the bulk copper oxide materials [54]. This can be due to quantum size effect of the synthesized nanomaterials [55]. The zeta potential of the tenorite nanoparticles under analysis as a function of $\mathrm{pH}$ is 
shown in Fig. 5. The results obtained indicate that the zero-charge point (ZCP) is $\sim 6.4$, with the surface of the particles being negatively and positively charged when $\mathrm{pH}$ is above or below this value, respectively.
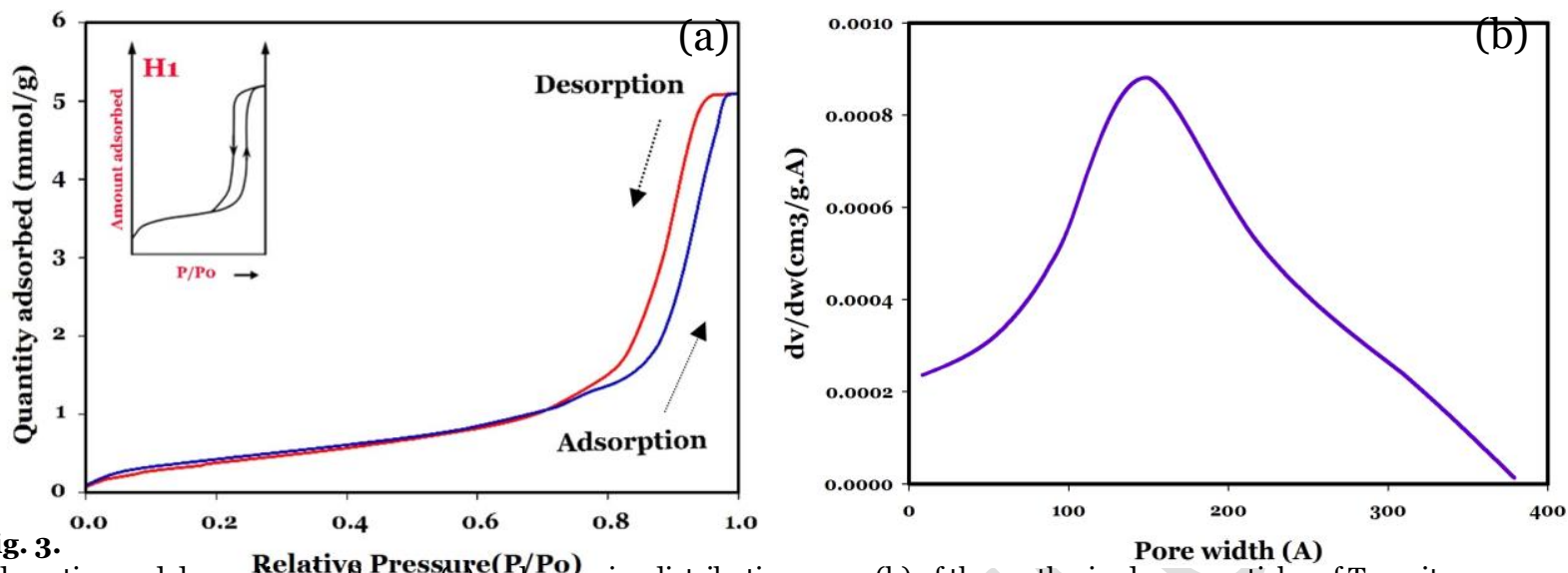

Fig. 3.
Adsorption and desorption isotherms (a) and pore size distribution curve (b) of the synthesized nanoparticles of Tenorite.

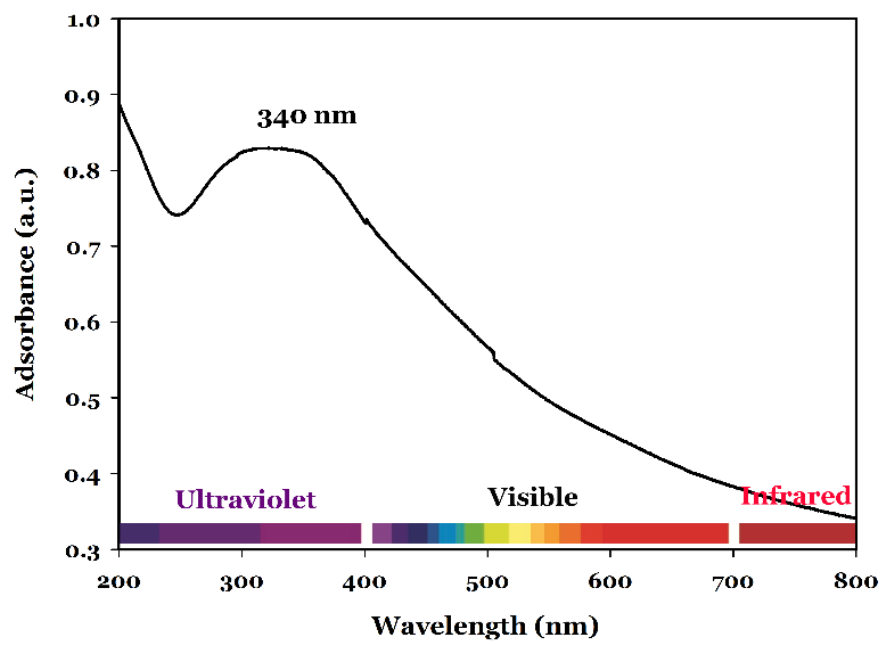

Fig. 4 .

UV-Vis spectrum of Tenorite nanoparticles prepared in this study.

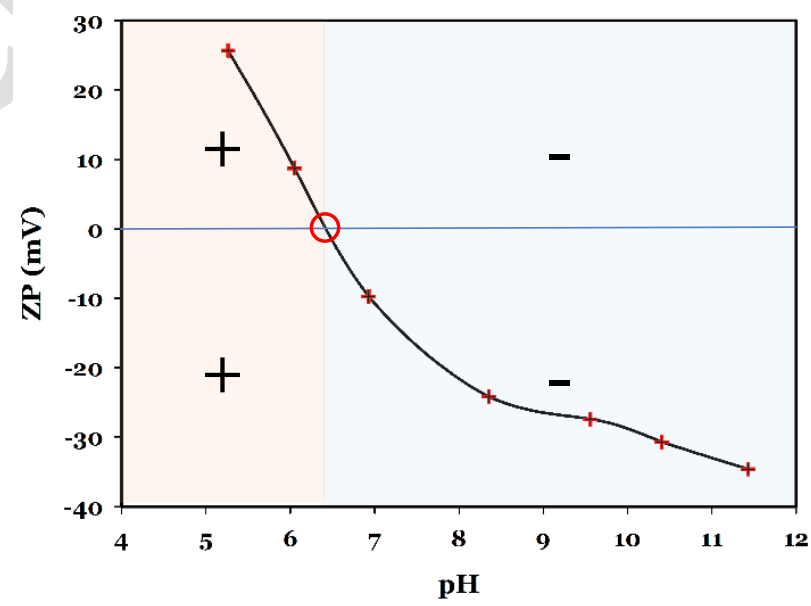

Fig. 5.

$$
\text { pH }
$$

$\mathrm{pH}$ dependence of $\mathrm{ZP}$ of the synthesized Tenorite nanoparticles. The point of zero charge is detected at $\mathrm{pH} \approx 6.4$. 


\subsection{Taguchi experimental design}

\subsubsection{Statistical analysis}

Data presented in Table 3 and displayed in Fig. 6 show the results obtained with the L-18 orthogonal array of the investigated parameters (reaction time, initial $\mathrm{pH}$, temperature, sonication time, and dosage of NMs) and their combined effects on the removal of TOC from the diluted BL effluents. The strongest statistical relevance is observed for the effects of reaction time (see Table 4), followed by the effects of initial $\mathrm{pH}$, sonication time, the dosage of $\mathrm{NMs}$, and temperature. The highest difference in the $\mathrm{S} / \mathrm{N}$ ratio between the various levels of an individual parameter belongs to the $\mathrm{S} / \mathrm{N}\left(\mathrm{Time}_{\mathrm{omin}}\right)-\mathrm{S} / \mathrm{N}\left(\mathrm{Time}_{5 \min }\right)$ as can be observed in Fig. 6 (a). This suggests that the removal reaction took place very quickly in the initial period of the experiments which then slowed down, reaching a kind of a plateau after 15 min, which further extends to $60 \mathrm{~min}$ of reaction time. The "initial step of the rapid reaction" for the oxidative treatment of BL was also observed by Zhang et al., [34].

Significant differences between the control condition without nanomaterials (NMs conc. $=0 \mathrm{~g} / \mathrm{L}$, $\mathrm{S} / \mathrm{N}$ ratio $=-8.90)$ and the experiments involving the application of various initial dosages of NMs (NMs conc. $=0.5 \mathrm{~g} / \mathrm{L}(\mathrm{S} / \mathrm{N}$ ratio $=8.82)$ and NMs conc. $=1 \mathrm{~g} / \mathrm{L}(\mathrm{S} / \mathrm{N}$ ratio $=9.50))$ are quite evident. The two main mechanisms might be involved in the treatment of this wastewater, including the adsorption of pollutants or their decomposition via advanced oxidation of organic compounds. In fact, the rate of hydroxyl radicals generated from the reaction of $\mathrm{O}_{2}$ and $\mathrm{H}_{2} \mathrm{O}\left(\frac{1}{4} \mathrm{O}_{2}+\frac{1}{2} \mathrm{H}_{2} \mathrm{O} \leftrightarrow \mathrm{OH}^{o}\right)$ in the presence of a catalyst [31] appears to be high during the initial stages of the reaction. Hydroxyl radicals are normally formed on the surface of the catalyst, facilitating the decomposition of organic pollutants due to catalytic activity of the prepared tenorite NMs. The observed TOC removal values (in \%) (response data) on the various experimental runs are shown in Tables 3 and 4. In all the cases, the standard deviation was less than $5 \%$ and average values were used for the Taguchi experimental design analysis.

Table 3. TOC removals and $\mathrm{S} / \mathrm{N}$ ratios for all experimental runs.

\begin{tabular}{lll}
\hline Run & TOC removal $(\sim \%)$ & S/N ratio $(\mathrm{dB})$ \\
\hline 1 & o & -80.0000 \\
2 & 0 & -80.0000 \\
3 & 0 & -80.0000 \\
4 & 25 & 28.0707 \\
5 & 23 & 27.3128 \\
6 & 0 & -80.0000 \\
7 & 29 & 29.2510 \\
8 & 26 & 28.2675 \\
9 & 16 & 24.3236 \\
10 & 34 & 30.5560 \\
11 & 17 & 24.5372 \\
12 & 18 & 25.2459 \\
13 & 21 & 26.2546 \\
14 & 19 & 25.5391 \\
15 & 16 & 23.9178 \\
16 & 40 & 31.9638 \\
17 & 22 & 26.8404 \\
18 & 17 & 24.4310 \\
\hline
\end{tabular}




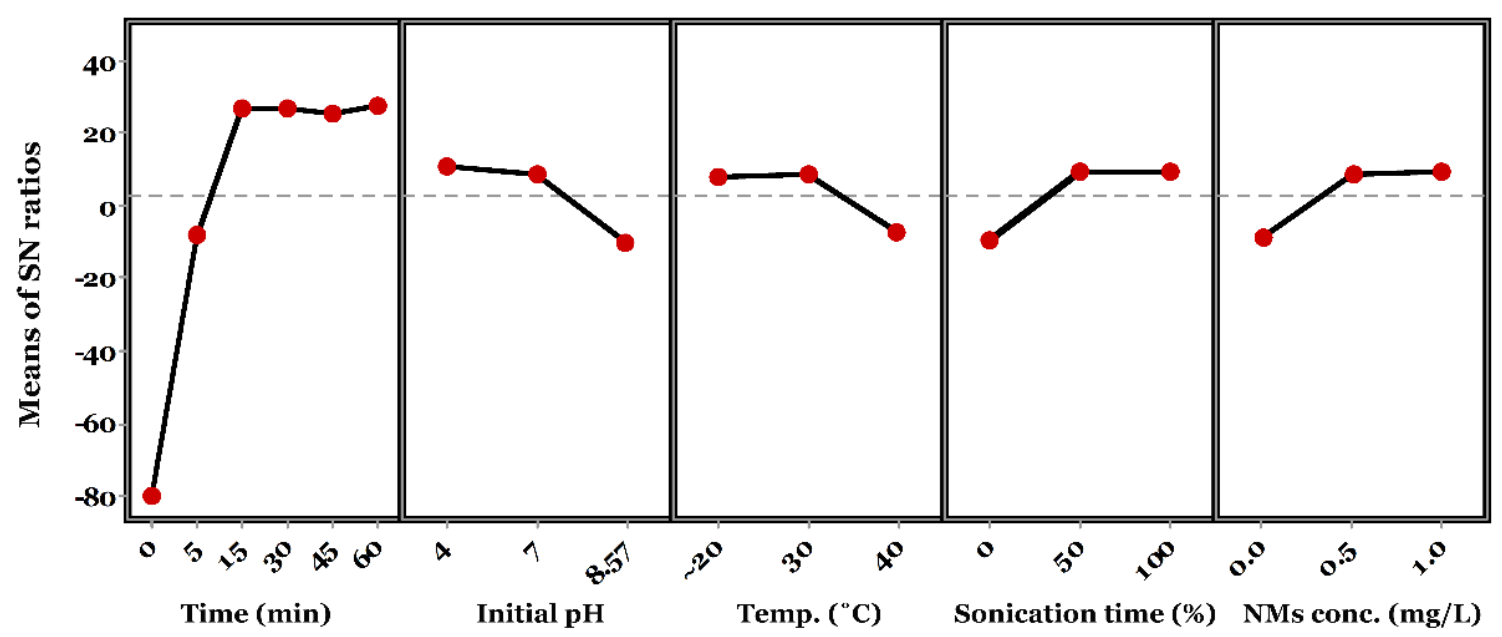

Fig. 6.

Variation of the calculated $\mathrm{S} / \mathrm{N}$ ratios for the studied experimental conditions: time, initial $\mathrm{pH}$, temperature, sonication time, and the amount of nanomaterials used.

Table 4. Signal to noise ratio (S/N), effect factor (Ef) and ranking (Rank) for each factor corresponding to the various studied experimental conditions.

\begin{tabular}{|c|c|c|c|c|c|c|c|c|c|c|}
\hline $\begin{array}{l}\text { Factor/ } \\
\text { Levels }\end{array}$ & $\begin{array}{l}\text { Reaction } \\
\text { Time (min) }\end{array}$ & $\begin{array}{l}\mathrm{S} / \mathrm{N} \\
(\mathrm{dB})\end{array}$ & $\begin{array}{l}\text { Initial } \\
\mathrm{pH}\end{array}$ & $\begin{array}{l}\mathrm{S} / \mathrm{N} \\
(\mathrm{dB})\end{array}$ & $\begin{array}{l}\text { Temperature } \\
\left({ }^{\circ} \mathrm{C}\right)\end{array}$ & $\begin{array}{l}\mathrm{S} / \mathrm{N} \\
(\mathrm{dB})\end{array}$ & $\begin{array}{l}\text { Sonication } \\
\text { time (\%) }\end{array}$ & $\begin{array}{l}\mathrm{S} / \mathrm{N} \\
(\mathrm{dB})\end{array}$ & $\begin{array}{l}\text { NMs } \\
\text { Conc. } \\
\text { (g/L) }\end{array}$ & $\begin{array}{l}\mathrm{S} / \mathrm{N} \\
(\mathrm{dB})\end{array}$ \\
\hline & 0 & -80.00 & 4 & 11.01 & $\sim 20$ & 7.95 & 0 & -9.37 & 0 & -8.90 \\
\hline & 5 & -8.21 & 7 & 8.75 & 30 & 8.75 & 50 & $9.5^{8}$ & 0.5 & 8.82 \\
\hline & 15 & 27.28 & $8.57^{a}$ & -10.35 & 40 & -7.28 & 100 & 9.22 & 1 & 9.50 \\
\hline & 30 & 26.78 & & & & & & & & \\
\hline & 45 & 25.24 & & & & & & & & \\
\hline & 60 & 27.74 & & & & 8 & & & & \\
\hline $\mathrm{E}_{f}$ & & 107.74 & & 21.36 & & 16.03 & & 18.95 & & 18.40 \\
\hline Rank & & 1 & & 2 & 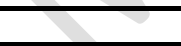 & 5 & & 3 & & 4 \\
\hline
\end{tabular}

The optimum initial $\mathrm{pH}$ for the removal of TOC was identified at $4(\mathrm{~S} / \mathrm{N}$ ratio $=11.01)$, while the natural $\mathrm{pH}$ of the effluents (8.57) resulted in the lowest treatment efficiency ( $\mathrm{S} / \mathrm{N}$ ratio $=-10.35)$ among the studied pHs. The initial $\mathrm{pH}$ plays a significant role in the removal of organic compounds from the studied effluents and the efficiency of the treatment is directly related to the surface charge of the NMs. adsorption can be considered the first step towards the removal of organic compounds which can further undergo the oxidation. At higher $\mathrm{pH}$ values, the $\mathrm{ZP}$ of the nanomaterials is negative, which can lead to a repulsion between the surface of the nanomaterials and the organic compounds (which are generally negatively charged [57,58]). Under these conditions, the majority of organic compounds in the effluents are degraded through free hydroxyl radicals, which is a relatively slow degradation process. Therefore, it is obvious that the removal efficiency under acidic conditions is improved. The optimal reaction temperature of $30^{\circ} \mathrm{C}(\mathrm{S} / \mathrm{N}$ ratio: 8.75) was also identified experimentally. The increase in the operating temperature to $40^{\circ} \mathrm{C}$ resulted in a slight reduction in the efficiency of TOC removal $(\mathrm{S} / \mathrm{N}$ ratio $=-7.28)$. It may be assumed that by increasing the temperature from $30^{\circ} \mathrm{C}$ to $40^{\circ} \mathrm{C}$, depletion in oxygen content (which occurs under elevated temperatures) has lead to a reduction of TOC removal from the effluents. It is evident that, under higher temperatures, the dissociation of these products can lead to the promotion of TOC removal from effluents [59]. 
Ultrasonic irradiation was also considered to be effective for the removal of TOC from the effluents. Although ultrasonic irradiation during the initial $50 \%$ of the reaction time $(\mathrm{S} / \mathrm{N}$ ratio $=9.58)$ has been identified as the most important factor/level after the initial $\mathrm{pH}$ of 4 , the longest ultrasonic irradiation up to $100 \%$ of the reaction time $(\mathrm{S} / \mathrm{N}$ ratio $=9.22)$ did not further improve the TOC removal from the effluents. When ultrasound is irradiated in bulk water, it caused cavitation which involves the growth and collapse of bubbles in the medium [28]. This phenomenon might have led to the generation of local temperature and pressure above $5000 \mathrm{~K}$ and 500 atm [60] and, as a result, thermal dissociation of water molecules in products that include hydroxyl radicals and hydrogen radicals $\left(\mathrm{H}_{2} \mathrm{O} \rightarrow \mathrm{OH}^{\bullet}+\mathrm{O}^{\bullet}\right)$ [61] might have occurred. The radicals generated will be involved in the decomposition of organic compounds in the presence of the catalyst. In general, it can be suggested that the rapid removal of TOC in the first $60 \mathrm{~min}$ may be due to the adsorption of pollutants on the surface and pores of the nanoparticles and the relatively slower degradation of compounds under solar irradiation. The experiments were designed to simulate the real conditions of wastewater treatment. Figure 7 presents the XRD (a) and SEM image (a and b) of tenorite NMs after the treatment of the black liquor under the optimum conditions. There were no significant changes in the composition and shape of the NMs after being used for treatment purposes. Therefore, nanomaterials can be reused several times, which is of great importance in terms of economic considerations.

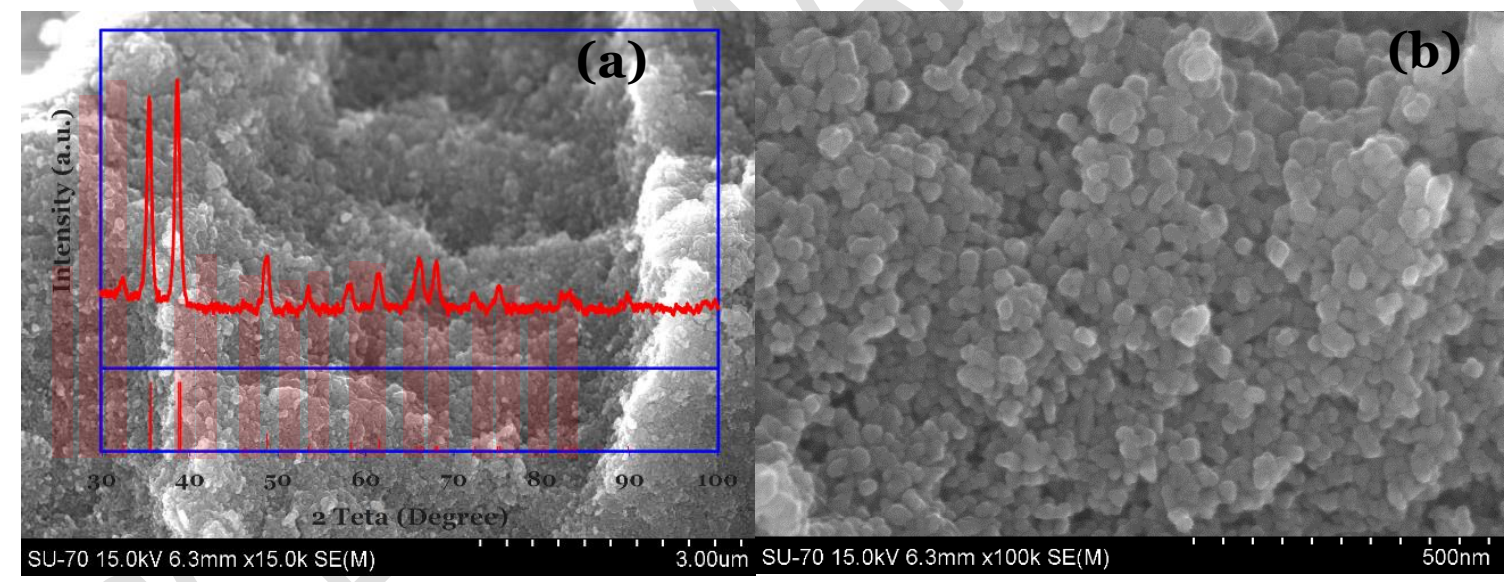

Fig. 7.

XRD (a) and SEM image (a, and b) of the Tenorite NMs after treatment of the black liquor under optimum conditions.

Until now, other efforts on the application of oxidation processes have been adopted for the treatment of black liquor from the pulp and paper industry. Such of the previously tested techniques generally utilize the oxidation treatment of the black liquor under intense conditions, such as high temperature and high pressure to oxidize the complicated organic compounds in the black liquor content. For instance, partial wet oxidation of kraft black liquor and wheat straw black liquor was carried out by Muddassar et al., [62] at $170-230^{\circ} \mathrm{C}$ only under oxygen gas, or in the presence of iron catalysts or $\mathrm{H}_{2} \mathrm{O}_{2}$, as an additional oxidant. Under the optimum conditions, the authors achieved 57-64\% average removal of lignin from the black liquor. Zhang and Chuang [56] employed the Pt-Pd-Ce/alumina catalyst at $463 \mathrm{~K}$ 
$\left(189^{\circ} \mathrm{C}\right.$ ) and a pressure of $2.2 \mathrm{MPa}$ wherein TOC removal (initial TOC: $1500 \mathrm{mg} / \mathrm{L}$ ) after $1 \mathrm{~h}$ reached up to $50 \%$.

Combination of various physico-chemical methods have also been reported for the treatment of black liquor effluents. The integration of photo-oxidation and post coagulation can be considered to be an effective method to this end. Helmy, et al., [63] combined bioremediation of black liquor effluents using eight different strains with the post-photo-Fenton reaction combined with lime coagulation to improve the removal efficiency and obtain suitable water for recycling from pulp and paper mill effluents. The authors achieved 47-100\% of Chemical Oxygen Demand (COD) removal (initial COD: $1790 \mathrm{mg} / \mathrm{L}$ ) using the combined system. Mahesh, Prasad, Mall, and Mishra et al., [64] tested the electrochemical degradation of black liquor effluents from agro-based paper mill using iron plate electrodes to achieve a maximum of $80 \%$ COD removal from black liquor, with an initial COD from 2000 to $2100 \mathrm{mg} / \mathrm{L}$. When the authors used the electrochemical treatment of black liquor followed by coagulation/flocculation, up to $91 \%$ of the COD removal was obtained. The electrocoagulation of black liquor from soda anthraqnone (AQ) pulping of wheat straw (initial COD: $1953 \mathrm{mg} / \mathrm{L}$ ) was also explored by Rastegarfar et al., [28]. The authors suggested that the efficiency of the treatment is directly related to the current densities of the aluminum electrodes and they achieved a maximum of up to $80 \%$ of COD removal from the effluents. Other methods, such as adsorption (e.g., on the anion exchange resins [32]), have been considered so far for the treatment of black liquor, but this method is yet struggling to meet out the economic considerations [65].

\section{Conclusions}

The present work deals with the degradation of highly polluted black liquor from the real pulp and paper industry using nano-sized tenorite prepared by ultrasound $\left(30-35 \mathrm{~nm}, \mathrm{BET}=35 \mathrm{~m}^{2} / \mathrm{g}\right.$, and Eg=3.6 $\mathrm{eV}$.). The application of Taguchi methodology indicated that the reaction time ( $\mathrm{E} f=107)$ is the most important parameter for the removal of TOC from the effluents. By manipulating the reaction conditions, removal of TOC up to $84 \%$ (initial TOC: $3516 \mathrm{mg} / \mathrm{L}$ ) was achieved under mild conditions of temperature and pressure and using $5 \mathrm{~g} / \mathrm{L}$ of the catalyst in 24 hours of the reaction, including 12 hours of solar irradiation ( 16000 lux). The mild operating conditions, without the need for input energy and the potential for recovery as well as reuse of catalysts, suggest that this is highly economical to treat such highly polluted effluents.

\section{Acknowledgments}

Thanks are due, for the financial support to CESAM - Center for Environmental and Marine Studies, POCI-01-0145-FEDER-007638 (FCT Ref. UID/AMB/50017/2020), and to the project CICECO-Aveiro Institute of Materials, UIDB/50011/2020 \& UIDP/50011/2020, financed by national funds through the Portuguese Foundation for Science and Technology /MCTES and the co-funding by the FEDER, within the PT2020 Partnership Agreement and Compete 2020. Thanks, are also due to FCT for the doctoral scholarship No. SFRH/BD/103695/2014 for the first author and No. SFRH/BD/140873/2018 for the 
second author. Thanks, are also due to the financial support from the PDM program, KU Leuven, Belgium.

\section{References}

[1] M. Kamali, I. Capela, M.E. Costa, Ultrasonic synthesis of zero valent iron nanoparticles for the efficient discoloration of aqueous solutions containing methylene blue dye, in: S. Ul-Islam, B.S. Butola (Eds.), Nanomater. Wet Process. Text., Wiley, 2018: pp. 261-284. https://doi.org/https://doi.org/10.1002/9781119459804.ch8.

[2] M. Kamali, M.E. V. Costa, G. Otero-Irurueta, I. Capela, Ultrasonic irradiation as a green production route for coupling crystallinity and high specific surface area in iron nanomaterials, J. Clean. Prod. 211 (2019) 185-197. https://doi.org/10.1016/j.jclepro.2018.11.127.

[3] M. Kamali, K.M. Persson, M.E. Costa, I. Capela, Sustainability criteria for assessing nanotechnology applicability in industrialwastewater treatment: Current status and future outlook, Environ. $\quad$ Int. $\quad 125$ (2019) 261-276. https://doi.org/https://doi.org/10.1016/j.envint.2019.01.055.

[4] M. Kamali, M. Davarazar, T.M. Aminabhavi, Single precursor sonochemical synthesis of mesoporous hexagonal-shape zero-valent copper for effective nitrate reduction, Chem. Eng. J. 384 (2020) 123359. https://doi.org/10.1016/j.cej.2019.123359.

[5] M. Khalaj, M. Kamali, Z. Khodaparast, A. Jahanshahi, Copper-based nanomaterials for environmental decontamination - An overview on technical and toxicological aspects, Ecotoxicol. Environ. Saf. 148 (2018) 813-824. https://doi.org/10.1016/j.ecoenv.2017.11.060.

[6] Y. Ling, M. Long, P. Hu, Y. Chen, J. Huang, Magnetically separable core - shell structural Y-Fe 2 O $3 @ \mathrm{Cu} / \mathrm{Al}-\mathrm{MCM}-41$ nanocomposite and its performance in heterogeneous Fenton catalysis, J. Hazard. Mater. 264 (2014) 195-202. https://doi.org/10.1016/j.jhazmat.2013.11.0o8.

[7] A. Nezamzadeh-ejhieh, Z. Salimi, Applied Catalysis A : General Heterogeneous photodegradation catalysis of o -phenylenediamine using $\mathrm{CuO}$ / X zeolite, "Applied Catal. A, Gen. 390 (2010) 110118. https://doi.org/10.1016/j.apcata.2010.09.038.

[8] M. Salavati-niasari, F. Davar, Synthesis of copper and copper ( I ) oxide nanoparticles by thermal decomposition of a new precursor, Mater. Lett. 63 (2009) 441-443. https://doi.org/10.1016/j.matlet.2008.11.023.

[9] G. Zhang, Z. Li, H. Zheng, T. Fu, Y. Ju, Y. Wang, Environmental Influence of the surface oxygenated groups of activated carbon on preparation of a nano $\mathrm{Cu} / \mathrm{AC}$ catalyst and heterogeneous catalysis in the oxidative carbonylation of methanol, "Applied Catal. B, Environ. 179 (2015) 95-105. https://doi.org/10.1016/j.apcatb.2015.05.001.

[10] J. Park, J. Lee, D. Kim, J. Lee, J. Ho, J. Gwak, Y. Eo, A. Cho, M.T. Swihart, S.S. Al-deyab, S. Ahn, D. Kim, S.S. Yoon, Acta Materialia Rapid supersonic spraying of $\mathrm{Cu}$ ( In , Ga )( S, Se ) 2 nanoparticles to fabricate a solar cell with 5.49 \% conversion ef fi ciency, Acta Mater. 123 (2017) 44-54. https://doi.org/10.1016/j.actamat.2016.10.027. 
[11] R. Etefagh, E. Azhir, N. Shahtahmasebi, Synthesis of $\mathrm{CuO}$ nanoparticles and fabrication of nanostructural layer biosensors for detecting Aspergillus niger fungi, Sci. Iran. 20 (2013) 10551058. https://doi.org/10.1016/j.scient.2013.05.015.

[12] S. Ahmad, A.B. Ziya, M.N. Ashiq, A. Ibrahim, S. Atiq, N. Ahmad, M. Shakeel, M.A. Khan, Improved magnetic and electrical properties of $\mathrm{Cu}$ doped $\mathrm{Fe}-\mathrm{Ni}$ invar alloys synthesized by chemical reduction technique, J. Magn. Magn. Mater. $419 \quad$ (2016) 125-130. https://doi.org/10.1016/j.jmmm.2016.06.033.

[13] G. Hao, J. Liu, H. Gao, L. Xiao, X. Ke, W. Jiang, F. Zhao, H. Gao, Preparation of Nano-Sized Copper $\beta$-Resorcylate ( $\beta$-Cu ) and its Excellent Catalytic Activity for the Thermal Decomposition of Ammonium Perchlorate, Propellants, Explos. Pyrotech. 40 (2015) 848-853. https://doi.org/10.1002/prep.201500006.

[14] B. Qu, X. Lu, Y. Wu, X. You, X. Xu, Synthesis of copper micro-rods with layered nano-structure by thermal decomposition of the coordination complex $\mathrm{Cu}$ ( BTA ) 2, NANOSCALE Res. Lett. 10:42 (2015) 1-5. https://doi.org/10.1186/s11671-015-0769-7.

[15] X. Luo, C. Li, D. Yang, F. Liu, Y. Chen, Sonochemical synthesis of porous $\mathrm{Cu} 2 \mathrm{O}$ e Cu hollow spheres and their, Mater. Chem. Phys. 151 (2015) 252-258. https://doi.org/10.1016/j.matchemphys.2014.11.062.

[16] Y. Li, W. Hong, Z. Xie, Z. Shen, Z. Wang, Synthesis and Microwave Dielectric Properties of CuDoped ZnAl2O4, Appl. Ceram. Technol. 13 (2016) 884-888. https://doi.org/10.1111/ijac.12417.

[17] S.S. Jushi, S. Mahumuni, RADIATION INDUCED SYNTHESIS AND CHARACTERIZATION OF COPPER NANOPARTICLES, NanoStruchuedMater. $10 \quad$ (1999) 1135-1144. https://doi.org/https://doi.org/10.1016/So965-9773(98)oo153-6.

[18] M.A. Alavi, A. Morsali, Ultrasound assisted synthesis of \{[Cu2(BDC)2(dabco)]. 2DMF.2H2O\} nanostructures in the presence of modulator; New precursor to prepare nano copper oxides, Ultrason. Sonochem. 21 (2014) 674-680. https://doi.org/10.1016/j.ultsonch.2013.09.017.

[19] M. Kamali, S.A. Alavi-Borazjani, Z. Khodaparast, M. Khalaj, A. Jahanshahi, E. Costa, I. Capela, Additive and additive-free treatment technologies for pulp and paper mill effluents: Advances, challenges and opportunities, Water Resour. Ind. 21 (2019) 100109. https://doi.org/10.1016/j.wri.2019.100109.

[20] M. Kamali, T. Gameiro, M.E. Costa, I. Capela, T.M. Aminabhavi, Enhanced biodegradation of phenolic wastewaters with acclimatized activated sludge - A kinetic study, Chem. Eng. J. 378 (2019) 122186. https://doi.org/10.1016/j.cej.2019.122186.

[21] M. Kamali, T. Gameiro, M.E. Costa, I. Capela, Anaerobic Digestion of Pulp and Paper Mill Wastes An Overview of the Developments and Improvement Opportunities, Chem. Eng. J. 298 (2016) 162-182. https://doi.org/10.1016/j.cej.2016.03.119.

[22] M.A. Hubbe, J.R. Metts, D. Hermosilla, M.A. Blanco, L. Yerushalmi, F. Haghighat, P. Lindholmlehto, Z. Khodaparast, Wastewater treatment and reclamation: A review of pulp and paper industry practices and opportunities, BIORESOURCES. 11 (2016) 7953-8091. 
https://doi.org/https://doi.org/10.1016/j.seppur.2011.07.002.

[23] A. Garg, Water Pollution from Pulp and Paper Mills, in: J.A. Daniels (Ed.), Adv. Environ. Res. Vol. 20, Nova Science Publishers, Inc, Hauppauge NY, 2012: pp. 245-252.

[24] P.K. Tewari, V.S. Batra, M. Balakrishnan, Efficient water use in industries: Cases from the Indian agro-based pulp and paper mills, J. Environ. Manage. 90 (2009) 265-273. https://doi.org/doi:10.1016/j.jenvman.2007.09.001.

[25] D.K. Tiku, A. Kumar, S. Sawhney, V.P. Singh, R. Kumar, Effectiveness of treatment technologies for wastewater pollution generated by Indian pulp mills, Env. Monit Assess. 132 (2007) 453-466. https://doi.org/10.1007/s10661-006-9548-3.

[26] D.K. Tiku, A. Kumar, R. Chaturvedi, S. Dayal, A. Manoharan, R. Kumar, Holistic bioremediation of pulp mill effluents using autochthonous bacteria, Int. Biodeterior. Biodegradation. 64 (2010) 173183. https://doi.org/https://doi.org/10.1016/j.ibiod.2010.01.001.

[27] M. Kamali, Z. Khodaparast, Review on recent developments on pulp and paper mill wastewater $\begin{array}{llllll}\text { treatment, } & \text { Ecotoxicol. } & \text { Environ. } & \text { Saf. } & 114 & \text { (2015) }\end{array}$ https://doi.org/10.1016/j.ecoenv.2014.05.005.

[28] N. Rastegarfar, R. Behrooz, N. Bahramifar, Electrocoagulation treatment of black liquor from soda-AQ pulping of wheat straw, Environ. Monit. Assess. 187 (2015) 1-9. https://doi.org/10.1007/s10661-014-4245-0.

[29] G. Huang, J.X. Shi, T.A.G. Langrish, A new pulping process for wheat straw to reduce problems with the discharge of black liquor, Bioresour. Technol. 98 (2007) 2829-2835. https://doi.org/10.1016/j.biortech.2006.09.029.

[30] M. Sainlez, G. Heyen, Comparison of supervised learning techniques for atmospheric pollutant monitoring in a Kraft pulp mill, J. Comput. Appl. Math. 246 (2013) 329-334. https://doi.org/doi:10.1016/j.cam.2012.06.026.

[31] K.B. Hewett, L.C. Anderson, M.P. Rosynek, J.H. Lunsford, Formation of Hydroxyl Radicals from the Reaction of Water and Oxygen over Basic Metal Oxides, J. Am. Chem. Soc. 7863 (1996) 69926997. https://doi.org/10.1021/ja960566g.

[32] D. Schmitt, C. Regenbrecht, M. Schubert, D. Schollmeyer, S.R. Waldvogel, Treatment of black liquor (BL) by adsorption on $\mathrm{AE}$ resins and a subsequent electrochemical degradation of $\mathrm{BL}$ to obtain vanillin, Holzforschung. 71 (2017) 35-41. https://doi.org/10.1515/hf-2015-0210.

[33] A.P. Buzzini, E.C. Pires, Evaluation of a upflow anaerobic sludge blanket reactor with partial recirculation of effluent used to treat wastewaters from pulp and paper plants, Bioresour. Technol. 98 (2007) 1838-1848. https://doi.org/10.1016/j.biortech.2006.06.030.

[34] A.P. Buzzini, E.P. Gianotti, E.C. Pires, UASB performance for bleached and unbleached kraft pulp synthetic wastewater treatment, Chemosphere. $59 \quad$ (2005) 55-61. https://doi.org/https://doi.org/10.1016/j.chemosphere.2004.09.102.

[35] A.P. Buzzini, E.C. Pires, Cellulose pulp mill effluent treatment in an upflow anaerobic sludge blanket reactor, $\quad$ Process $\quad$ Biochem. $38 \quad$ (2002) 707-713. 
https://doi.org/https://doi.org/10.1016/So032-9592(02)o0190-5.

[36] A.. Buzzini, I.K. Sakamoto, M.B. Varesche, E.C. Pires, Evaluation of the microbial diversity in an UASB reactor treating wastewater from an unbleached pulp plant, Process Biochem. 41 (2006) 168-176. https://doi.org/https://doi.org/10.1016/j.procbio.2005.06.009.

[37] B.A.E. Ben-Arfa, I.M.M. Salvado, J.R. Frade, R.C. Pullar, Fast route for synthesis of stoichiometric hydroxyapatite by employing the Taguchi method, Mater. Des. 109 (2016) 547-555. https://doi.org/10.1016/j.matdes.2016.07.083.

[38] APHA, Standard Methods for the Examination of Water and Wastewater, 21st ed. American Public Health Association, Washington, DC, USA, (2005).

[39] B. Charmas, R. Leboda, Effect of surface heterogeneity on adsorption on solid surfaces Application of inverse gas chromatography in the studies of energetic heterogeneity of adsorbents, J. Chromatogr. A. 886 (2000) 133-152. https://doi.org/10.1016/s0021-9673(00)00432-5.

[40] F. Thielmann, Introduction into the characterisation of porous materials by inverse gas $\begin{array}{llllll}\text { chromatography, } & \text { J. } & \text { Chromatogr. } & \text { A. } & 1037 & \text { (2004) 115-123. }\end{array}$ https://doi.org/10.1016/j.chroma.2004.03.060.

[41] E.P. Barrett, L.G. Joyner, P.P. Halenda, The Determination of Pore Volume and Area Distributions in Porous Substances. I. Computations from Nitrogen Isotherms, J. Am. Chem. Soc. 73 (1951) 373-380. https://doi.org/10.1021/jao1145a126.

[42] A. Van Tran, Removal of cod and color loads in bleached kraft pulp effluents by bottom ashes from boilers, Environ. Technol. 29 (2008) 775-784. https://doi.org/10.1080/09593330801987020.

[43] M. Ibănescu, V. Muşat, T. Textor, V. Badilita, B. Mahltig, V. Mus, Photocatalytic and antimicrobial $\mathrm{Ag} / \mathrm{ZnO}$ nanocomposites for functionalization of textile fabrics, J. Alloys Compd. 610 (2014) 244249. https://doi.org/10.1016/j.jallcom.2014.04.138.

[44] P. Devi, A.K. Saroha, Simultaneous adsorption and dechlorination of pentachlorophenol from effluent by $\mathrm{Ni}$ - ZVI magnetic biochar composites synthesized from paper mill sludge, Chem. Eng. J. 271 (2015) 195-203. https://doi.org/10.1016/j.cej.2015.02.087.

[45] R. Norouzbeigi, S. Majdabadi Farahani, Modified combustion synthesis of Nano-NiFe2O4: Optimization using Taguchi experimental design, J. Magn. Magn. Mater. 384 (2015) 289-295. https://doi.org/10.1016/j.jmmm.2015.02.055.

[46] K. Do Kim, D.N. Han, H.T. Kim, Optimization of experimental conditions based on the Taguchi robust design for the formation of nano-sized silver particles by chemical reduction method, Chem. Eng. J. 104 (2004) 55-61. https://doi.org/10.1016/j.cej.2004.08.003.

[47] D. Mubarakali, J. Arunkumar, P. Pooja, Synthesis and characterization of biocompatibility of tenorite nanoparticles and potential property against biofilm formation, Saudi Pharm. J. 23 (2015) 421-428. https://doi.org/10.1016/j.jsps.2014.11.007.

[48] E. Buarod, S. Pithakratanayothin, S. Naknaka, P. Chaiyasith, Facile synthesis and characterization of tenorite nanoparticles from gas-atomized $\mathrm{Cu}$ powder, Powder Technol. 269 (2015) 118-126. https://doi.org/10.1016/j.powtec.2014.08.052. 
[49] S. Reddy, B.E.K. Swamy, H. Jayadevappa, CuO nanoparticle sensor for the electrochemical determination of dopamine, Electrochim. Acta. $61 \quad$ (2012) 78-86. https://doi.org/10.1016/j.electacta.2011.11.091.

[50] Z.A. ALOthman, A Review: Fundamental Aspects of Silicate Mesoporous Materials, Materials (Basel). 5 (2012) 2874-2902. https://doi.org/10.3390/ma5122874.

[51] H.E. Bergna, The Colloid Chemistry of Silica; Advances in chemistry series 234, American Chemical Society, Washington, DC, USA, 1994.

[52] M.P. Neupane, I.S. Park, T.S. Bae, M.H. Lee, Sonochemical assisted synthesis of nano-structured titanium oxide by anodic oxidation, J. Alloys Compd. 581 (2013) 418-422. https://doi.org/10.1016/j.jallcom.2013.07.110.

[53] G. Varughese, V. Rini, S.P. Suraj, K.T. Usha, CHARACTERISATION AND OPTICAL STUDIES OF COPPER OXIDE NANOSTRUCTURES DOPED WITH LANTHANUM IONS, Adv. Mater. Sci. 4 (2014) 51-60. https://doi.org/DOI: 10.2478/adms-2014-0021.

[54] M. Kaur, K.P. Muthe, S.K. Despande, S. Choudhury, J.B. Singh, N. Verma, S.K. Gupt, J.V. Yakhmi, Growth and branching of $\mathrm{CuO}$ nanowires by thermal oxidation of copper, J. Cryst. Growth. 289 (2006) 670-675. https://doi.org/10.1016/j.jcrysgro.2005.11.111.

[55] S. Mandal, J. Wang, R.E. Winans, L. Jensen, A. Sen, Quantum size effects in the optical properties of ligand stabilized aluminum nanoclusters, J. Phys. Chem. C. 117 (2013) 6741-6746. https://doi.org/10.1021/jp310514Z.

[56] Q. Zhang, K.T. Chuang, Kinetics of wet oxidation of black liquor over a Pt-Pd-Ce/alumina catalyst, Appl. Catal. B Environ. 17 (1998) 321-332. https://doi.org/10.1016/So926-3373(98)ooo16-2.

[57] L.V. Watershed, R. Mountain, N. Park, J. Baron, D. Mcknight, A.S. Denning, Sources of dissolved and particulate organic material in Loch Vale Watershed, Rocky Mountain National Park, Colorado, USA, Biogeochemistlry. 15 (1991) 89-11o. https://doi.org/10.1007/BFoooo3219.

[58] H.Q. Dang, L.D. Nghiem, W.E. Price, Factors governing the rejection of trace organic contaminants by nanofiltration and reverse osmosis membranes, Desalin. Water Treat. 52 (2014) 589-599. https://doi.org/10.1080/19443994.2013.826851.

[59] A. Garg, I.M. Mishra, S. Chand, Catalytic wet oxidation of the pretreated synthetic pulp and paper mill effluent under moderate conditions, Chemosphere. 66 (2007) 1799-1805. https://doi.org/10.1016/j.chemosphere.2006.07.038.

[6o] A. Miyaji, M. Kohno, Y. Inoue, T. Baba, Hydroxyl radical generation by dissociation of water molecules during 1.65 MHz frequency ultrasound irradiation under aerobic conditions, Biochem. Biophys. Res. Commun. 483 (2017) 178-182. https://doi.org/10.1016/j.bbrc.2016.12.171.

[61] E.B. Flint, K.S. Suslick, The temperature of cavitation, Science (80-. ). 253 (1991) 1397-1399. https://doi.org/DOI: 10.1126/science.253.5026.1397.

[62] H.R. Muddassar, M.H. Sipponen, K. Melin, D. De Kokkonen, O. Pastinen, S. Golam, Eff ects of Catalysts and $\mathrm{pH}$ on Lignin in Partial Wet Oxidation of Wood and Straw Black Liquors, Ind. Eng. Chem. Res. 54 (2015) 7833-7840. https://doi.org/10.1021/acs.iecr.5bo1764. 
[63] S.M. Helmy, S. El Rafie, M.Y. Ghaly, Bioremediation post-photo-oxidation and coagulation for black liquor effleunt treatment Bioremediation post-photo-oxidation and coagulation for black liquor effleunt treatment, Desalination. 158 (2003) 331-339. https://doi.org/10.1016/Soo119164(03)00472-7.

[64] S. Mahesh, B. Prasad, I.D. Mall, I.M. Mishra, Electrochemical degradation of pulp and paper mill wastewater. Part 1. COD and color removal, Ind. Eng. Chem. Res. 45 (2006) 2830-2839. https://doi.org/10.1021/ieo514096.

[65] M. Kamali, M.E. Costa, T.M. Aminabhavi, I. Capela, Sustainability of treatment technologies for industrial biowastes effluents, Chem. Eng. J. $370 \quad$ (2019) 1511-1521. https://doi.org/10.1016/j.cej.2019.04.010. 